\title{
Preexisting Condition
}

National Cancer Institute

\section{Source}

National Cancer Institute. Preexisting Condition. NCI Thesaurus. Code C54056.

A health condition or medical problem that was diagnosed or treated before a specific date. 